\title{
KNOWLEDGE AND USE OF STROKE ASSESSMENT SCALES BY PHYSIOTHERAPISTS IN SELECTED NIGERIAN HEALTH INSTITUTIONS
}

\author{
Journal website at; \\ http://mrtbjournal.org/index.php/njmr/issue/current/showToc \\ ${ }^{1}$ UAC OKAFOR, ${ }^{2}$ BN BIRABI, ${ }^{3}$ A OKUNUGA \\ ${ }^{I}$ Physiotherapy Department, College of Medicine, University of Lagos \\ ${ }^{2}$ Medical Department, Shell Petroleum Development Company, Port Harcourt \\ ${ }^{3}$ Physiotherapy Department, General Hospital, Lagos, Lagos State \\ Correspondence to: $\mathbf{B N}$ \\ Birabi \\ therapyezel@hotmail.com
}

\begin{abstract}
SUMMARY
Background \& Objective: Stroke assessment scales are top among core British National Clinical Guidelines for Stroke that has been strongly advocated by the Intercollegiate Stroke Working Party (ISWP). These clinical assessment measures have been studied for validity and reliability and have been in use globally by clinicians for over three decades. Knowledge and use of stroke scales by Physiotherapists in Nigeria will be a strong tool in improving the quality of care and life of stroke survivors. This study therefore sought to evaluate the level of knowledge, availability and utilization of stroke scales among Physiotherapists in Nigeria.
\end{abstract}

Methods: Two hundred (200), two-part, 18-item, self administered questionnaires were distributed to a convenient sample of Nigerian Physiotherapists practicing in urban and suburban hospitals spread over four out of six geopolitical zones of Nigeria. One hundred and eighty (180) respondents $(90 \%)$ returned fully completed questionnaires.

Results: Of the 180 respondents, $66.7 \%$ had knowledge of stroke scales though only $28 \%$ claimed they were taught in their training institutions. Three types of scales were mainly available among $30.6 \%$ of respondents in their institutions of practice. However, $70 \%$ of these respondents to whom these scales were available do not utilize them mostly due to high patient load and time constraint in clinical setting. All participants (100\%) desired knowledge and availability of the scales while $90 \%$ strongly agreed that stroke scales make the patient, essential part of goal setting and accelerates his reintegration into the society after stroke.

Conclusion: Knowledge of stroke assessment scales is low among Physiotherapists in Nigeria. Even among those who have knowledge of the scales, there is low availability and utilization in the treatment of stroke. Therefore, improvement in knowledge, availability and utilization of stroke assessment scales by Physiotherapists in Nigeria is imperative.

Key words; Stroke Assessment Scales, Physiotherapy

\section{INTRODUCTION}

A Stroke scale represents a useful tool for estimating the severity of stroke at onset and for assessing prognostic information while in hospital. It consists of several variables for observing stroke signs and symptoms, and each variable is categorized for scoring. Globally, stroke scales aim and pay attention to areas such as level of consciousness, disability, activities of daily living mental status screening, assessment of motor function, balance, mobility, speech and language function, health status and quality of life measures (Karen et al., 2003; Maas et al., 2009).

Other aspects include depression and family assessment scales. Usually the total score for a patient is calculated from an integration of the scores for each of the measured variables. Stroke scales have been available as a valuable clinical assessment tool for over three decades providing desirable outcomes for evidence based practice (Karen et al., 2003). According to the American Heart 
Association (1998), stroke scales are classified as follows: (1) Pre-hospital Stroke Assessment Tools which include Cincinnati Stroke Scale, Los Angeles Pre-hospital Stroke Screen (LAPSS) and the ABCD Score, (2) Acute Assessment Scales include Canadian Neurological Scale (CNS), European Stroke Scale, Glasgow Coma Scale (GCS), Hemispheric Stroke Scale, Hunt \& Hess Scale, Mathew Stroke Scale, NIHSS, Orgogozo stroke scale, Oxford shire community stroke project classification (Bamford), Scandinavian Stroke Federation Scale and the World of Neurological Surgeons Grading System for Subarachnoid Haemorrhage Scale, (3) Functional Assessment Scales include Berg Balance Scale, Lawton IADL Scale, Modified Rankin Scale, Stroke Impact Scale (SIS) and the Stroke Specific Quality of Life Measure and (4) Outcome Assessment Scales include American Heart Association Stroke Outcome Classification (AHA SOC), Barthel Index, Functional Independence Measurement (FIM), Glasgow Outcome Scale (GOS), Health Survey SF-36 ${ }^{\mathrm{TM}} \&$ SF-12 ${ }^{\mathrm{TM}}$ and the Community Integration Questionnaire (Rothwell et al., 2005). Among the commonly used stroke scales are National Institute of Health Stroke Scale (NIHSS), Barthel Index, Modified Rankin Scale (MRS), Cincinnati Stroke Scale, Glasgow Outcome Scale, Canadian Neurological scale, Hunt-Hess Scale, European Stroke scale, Functional Independence Measure (FIM) and the Stroke Specific Quality of Life (SS-QoL) scale (William et al., 1999; Hantson et al., 1994). National Institute of Health Stroke Scale (NIHSS) provides a quantitative assessment of the neurological examination findings that are most relevant to stroke patients. It assesses neurological impairment, providing a measure of the severity of the stroke and was developed specifically for use in acute stroke trials. The NIHSS scale awards between 0 grade (for best performance) and 5 (for inactivity or worst activity) and assesses the following; level of consciousness (LOC), best gaze and visual aspects, facial palsy, motor arm and leg, limb ataxia, sensory aspects, best language and dysarthria, as well as extinction and inattention (Rothwell et al., 2005; Maas et al., 2009). Modified Rankin Scale is the most commonly used global disability scale for assessing stroke patients. It is a simple measure of independence that is primarily used in the rehabilitation phases of stroke. The scales include: no symptoms, no significant disability despite symptoms, slight disability; unable to carry out all previous activities, moderate disability requiring some help, moderately severe disability, unable to walk without assistance, severe disability, bedridden, incontinent, dead (Banks and Marotta 2007). Barthel Index focuses on measurement of activities of daily living and is typically used for monitoring patients during the rehabilitation phases of stroke. This scale assesses the need for supervision or assistance in common activities awarding grades between 0 for inability to 15 for independence in aspects of the following: feeding, bathing, grooming, dressing, bowels, bladder, toilet use, transfers (bed to chair and back), mobility (on level surfaces) and stairs mobility (Hsueh et al., 2002). 
Table 1: Relative Strengths of Some Standard Assessment Scales in Stroke (U.S Agency for Health Care Policy and Research, 1995).

\begin{tabular}{|c|c|c|c|c|}
\hline Type & Name and Source & $\begin{array}{l}\text { Approximate } \\
\text { Time to } \\
\text { Administer }\end{array}$ & Strengths & Weaknesses \\
\hline $\begin{array}{l}\text { Level-of-consciousness } \\
\text { scale }\end{array}$ & Glasgow Coma Scale & 2 minutes & Simple, valid, reliable. & None observed. \\
\hline \multirow[t]{2}{*}{ Stroke deficit scales } & NIH Stroke Scale & 2 minutes & $\begin{array}{l}\text { Brief, reliable, can be administered } \\
\text { by non-neurologists. }\end{array}$ & Low sensitivity. \\
\hline & $\begin{array}{l}\text { Canadian Neurological } \\
\text { Scale }\end{array}$ & 5 minutes & Brief, valid, reliable. & $\begin{array}{l}\text { Some useful measures } \\
\text { omitted. }\end{array}$ \\
\hline Global disability scale & Rankin Scale & 5 minutes & $\begin{array}{l}\text { Good for overall assessment } \\
\text { of disability. }\end{array}$ & $\begin{array}{l}\text { Walking is the only } \\
\text { explicit assessment } \\
\text { criterion. Low sensitivity. }\end{array}$ \\
\hline \multirow{2}{*}{$\begin{array}{l}\text { Measures of disability/ } \\
\text { activities of daily living } \\
\text { (ADL) }\end{array}$} & Barthel Index & $5-10$ minutes & $\begin{array}{l}\text { Widely used for stroke. Excellent } \\
\text { validity and reliability. }\end{array}$ & $\begin{array}{l}\text { Low sensitivity for high- } \\
\text { level functioning. }\end{array}$ \\
\hline & $\begin{array}{l}\text { Functional } \\
\text { Independence Measure } \\
\text { (FIM) }\end{array}$ & 40 minutes & $\begin{array}{l}\text { Widely used for stroke. Measures } \\
\text { mobility, ADL, cognition, } \\
\text { functional communication. }\end{array}$ & $\begin{array}{l}\text { "Ceiling" and "floor" } \\
\text { effects. }\end{array}$ \\
\hline \multirow[t]{2}{*}{$\begin{array}{l}\text { Assessment of motor } \\
\text { function }\end{array}$} & Fugl-Meyer & $30-40$ minutes & $\begin{array}{l}\text { Extensively evaluated measure. } \\
\text { Good validity and reliability for } \\
\text { assessing sensorimotor function } \\
\text { and balance. }\end{array}$ & $\begin{array}{l}\text { Considered too complex } \\
\text { and time-consuming by } \\
\text { many. }\end{array}$ \\
\hline & $\begin{array}{l}\text { Motor Assessment } \\
\text { Scale }\end{array}$ & 15 minutes & $\begin{array}{l}\text { Good, brief assessment of } \\
\text { movement and physical } \\
\text { mobility. }\end{array}$ & $\begin{array}{l}\text { Reliability assessed only } \\
\text { in stable patients. } \\
\text { Sensitivity not tested. }\end{array}$ \\
\hline \multirow{3}{*}{$\begin{array}{l}\text { Balance assessment } \\
\text { Mobility assessment }\end{array}$} & Motricity Index & 5 minutes & $\begin{array}{l}\text { Brief assessment of motor } \\
\text { function of arm, leg, and trunk. }\end{array}$ & Sensitivity not tested. \\
\hline & $\begin{array}{l}\text { Berg Balance } \\
\text { Assessment }\end{array}$ & 10 minutes & $\begin{array}{l}\text { Simple, well established with } \\
\text { stroke patients, sensitive to change. }\end{array}$ & None observed. \\
\hline & $\begin{array}{l}\text { Rivermead Mobility } \\
\text { Index }\end{array}$ & 5 minutes & $\begin{array}{l}\text { Valid, brief, reliable test of } \\
\text { physical mobility. }\end{array}$ & Sensitivity not tested. \\
\hline
\end{tabular}

\section{METHODS:}

Two hundred (200), two-parts, 18 items, self administered questionnaires were distributed to a convenient sample of Nigerian Physiotherapists. One hundred and eighty (180) respondents $(90 \%)$ returned fully completed questionnaires. One hundred and eighty Physiotherapists who practice in urban and sub-urban hospitals spread over four out of the six geopolitical zones of Nigeria participated in the study. They worked mainly in teaching hospitals, Federal Medical Centres, Specialist and General hospitals (where most stroke patients are referred to and treated). These health facilities are also predominantly located in cities and towns where Physiotherapy training institutions are located (implying high concentration of Physiotherapists) with greater access to the internet for possible preview or downloading of these various stroke scales for their use in patient care. Respondents were Physiotherapists who had between one (1) and thirty five (35) years of post qualification experience and had obtained between first degree and doctorate degree (with both undergraduate and postgraduate education completed in Nigeria).

\section{RESULTS}

Out of the 180 respondents, $120(66.7 \%)$ had knowledge of stroke scales while $33.3 \%$ had no knowledge. A total of 50 respondents (28\%) were taught stroke scales either at the undergraduate or postgraduate levels in Nigerian training institutions whereas $130(72 \%)$ were not taught at either levels. Only three types of stroke scales were utilized among $55(30.56 \%)$ respondents in their various institutions of clinical practice. These were the NIHSS, Barthel Index and the Modified Rankin Scale (MRS). $70 \%$ of these 55 respondents to whom these scales are available do not put them into clinical use as a result of factors described as time constraint and high patient workload. $114(95 \%)$ of the respondents who had knowledge of stroke scales agreed that stroke scales could be beneficial to both patient and clinician and enhances evidence based practice. All 60 respondents (33\%) who had no knowledge of the scales desired knowledge and availability, while $125(69.4 \%)$ of the entire 180 respondents desired its availability. $90 \%$ of those who have knowledge of the scales strongly agreed that stroke scales make stroke patients an essential part of goal setting during 
rehabilitation, improves their general quality of life and accelerates early social reintegration into the society after stroke.

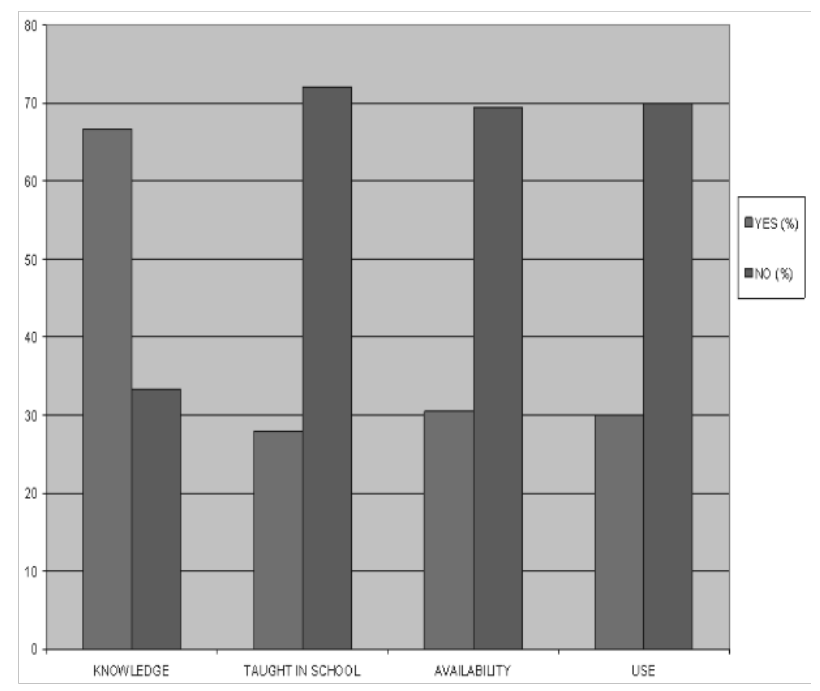

DISCUSSION \& CONCLUSION: The Intercollegiate Stroke Working Party (ISWP) emphasized timely and multidisciplinary patient assessment using a formal protocol in documented form and carried out within 72 hours of patient admission after stroke. It further stressed the need for patient goalsetting (short and long term goals) which must be meaningful, challenging but achievable (Fumio et al., 2001; ISWP, 2002). Result from this study indicates poor knowledge, availability and low utilization of these scales among physiotherapists in Nigeria. Even among the respondents who have knowledge and access to the scales, only $30 \%$ utilize them. These findings are in congruence with that reported by Akinpelu and Eluchie who studied the familiarity with, knowledge, and utilization of standardized outcome measures (SOM) among physiotherapists in Nigeria (Akinpelu and Eluchie, 2006). They reported low respondents' knowledge about the SOM $(3.1 \pm 2.5)$, which correlated positively and significantly ( $p$ $<0.05$ ) with their levels of familiarity with and utilization of the SOM. Also in a study to investigate the successful implementation of the NIHSS by Nurses who work in stroke units (Richardson et al., 2006), an initial survey indicated that the nurses felt that the NIHSS was too time consuming and was not consistent between users. They also felt incompetent or uncomfortable in using the scale and had difficulty locating the NIHSS forms and the resource booklet to assist in performing the scale. Following an intervention, which involved education on the NIHSS to the nurses in various forms (in-service sessions on the pathophysiology and neurological assessment of stroke by the unit's neuroscience clinical nurse specialist (CNS), and by viewing of a nationally recognized videotape of a certified neurologist administering the NIHSS), the percentage of nurses who had experience with the scale increased (from $57 \%$ to $97 \%$ ), as did the percentage who kn ew w here to find NIHSS materials (from $51 \%$ to $100 \%$ ).

The results therefore imply that poor knowledge, non-availability and ineffective use of stroke scales reflect negatively on the quality of therapeutic outcome among stroke survivors. This study therefore strongly recommends improved knowledge, availability and use of stroke scales as well as urgent creation of exclusive stroke clinics/ units as emergency (acute) routine care centers. Such geographically defined, conducive area should be staffed by physicians, physiotherapists, nurses, and other personnel skilled in the care and rehabilitation of stroke patients. This will enhance specialization and certainly optimize rehabilitation outcome. Finally, there is need for timely development of Nigerian and African indigenous stroke assessment scales to further address various peculiar socio-cultural factors, including environmental and language barriers.

\section{REFERENCES}

- Akinpelu OA, Eluchie NC (2006). Familiarity with, knowledge, and utilization of standardized outcome measures among physiotherapists in Nigeria. Physiotherapy Theory and Practice. 22(2): 61-72

- American Heart Association (1998). The A.H.A Stroke Outcome Classification: Executive Summary Circulation. 97:2474-2478.

- Banks JL and Marotta CA (2007). Outcomes validity and reliability of the modified Ranking scale: Implications for stroke clinical trials; a literature review and synthesis. Stroke. 38 (3): 1091-1096.

- Fumio Gotoh, Yasuo Terayama, Takahiro Amano (2001). Development of a novel, weighted quantifiable stroke scale; Stroke. 32: 1800-1807.

- Hantson L, De Weerdt W et al., (1994).The European stroke scale. Stroke. 25: 2215- 2219.

- Hsueh I, Lin J, Jeng J, and Hsieh C (2002).Comparison of the Psychometric characteristics of the functional independence measure, 5 item Barthel index and 10 item Barthel index with patients with stroke. J. Neurol Neurosurg Psychiatry 73(2):188-190

- Intercollegiate Working Party for Stroke (2002).National Clinical Guidelines for Stroke, 2nd edn. London: Royal College of Physicians 2002. available at http:// www.rcplondon.ac.uk/pubs/books/stroke/index.htm.

- Karen CJ, Alfred FC, Douglas PW, and Clarke H (2003). Predicting outcome in ischaemic stroke; External validation of predictive risk models. Stroke 34(1):200-202.

- Maas MB, Furie KL, Lev MH, Hakan A, Singhal AB, David $M$ et al., (2009). NIHSS score is poorly predictive of proximal occlusions in acute cerebral ischaemia. Stroke. 40: 2988-2993. 
- Richardson Jenny; Murray Diana; House Ken; Lowenkopf Ted (2006) Successful implementation of the National Institutes of Health Stroke Scale on a Stroke/Neurovascular Unit. J Neurosci Nurs. 38(4):309-314.

- Rothwell P, Giles M, Flossmann E, Lovelock C, Redgrave J, Warlow C, \& Mehta Z (2005). A simple tool to identify individuals at high early risk of stroke after a transient ischaemic attack: the ABCD score. The Lancet 366:29-36.
- U.S Agency for Health Care Policy and Research (1995). Preferred Standard Instrument for patient assessment in stroke. Publication no. 95-0663

- William L.S et al., (1999). Development of a stroke quality of life scale. Stroke (7)1362-9 consequences of falls due to stroke: a systematic inquiry. International Rehabilitation Medicine. 2: 177-80. 